\title{
PERBEDAAN KUALITAS GAMBAR MRI 0,3 TESLA ANTARA METODE GRAPPA DAN METODE PERUBAHAN NILAI PARAMETER DENGAN METODE RUTIN (Studi Pada Pemeriksaan MRI Vertebra Lumbal Potongan Sagital T2 FSE RSUD Prof. Dr. Margono Soekardjo Purwokerto Pada Pasien Dengan Lumbar Disorders)
}

\section{DIFFERENCE IMAGE QUALITY MRI 0,3 TESLA BETWEEN GRAPPA METHOD AND CHANGE PARAMETER VALUE METHOD WITH ROUTINE METHOD}

(Studies in MRI Examination Of Lumbar Spine Pieces Sagittal T2 FSE Prof. Dr.MargonoSoekardjoPurwokerto Hospital In Patients With Lumbar Disorders)

\author{
Panji Wibowo Nurcahyo ${ }^{1)}$, Ari Suwondo ${ }^{2)}$, Hermina Sukmaningtyas ${ }^{3)}$ \\ ${ }^{1)}$ Health Polytechnics of Semarang-Indonesia \\ ${ }^{2)}$ Diponegoro University, Semarang \\ ${ }^{3)}$ Central Hospital of Dr. Kariadi, Semarang \\ e-mail: 007.particle@gmail.com
}

\begin{abstract}
Background : Artefact degrade image quality. Motion artefact can be minimized by reducing scan time. The use of GRAPPA and change the value of TR, NEX and phase enchoding can reduce scan time. This study aims to determine the difference between MRI image quality of the GRAPPA method and routine method with change the value Phase enc. Dir., FOV phase, TR, TE, NEX, concatenation, base resolution, phase resolution and bandwidth by routine method MRI examination of lumbar spine sagittal T2 FSE in Prof. Dr. Margono Soekardjo hospital in patients with lumbar disorders.

Methods : Quasi experiments with equivalent posttest only control group design in 25 respondents were obtained in consecutive sampling. Each respondent was given three treatments with different method. Qualitative assessment was done on the MRI images results of the third treatment. Presence or absence of an overview assessment results HNP, spondylosis and degenerative disc analyzed with Cochran test while the level of clarity of the ligamentum flavum, thecal sac, intervertebral disc, vertebral body and the spinal cord was analyzed by Friedman test. Results : Cochran test produces a $\mathrm{p}$ value $>0,05$, while the friedman test results were followed by post hoc analysis resulted $\mathrm{p}$ value $<0,05$. The highest mean value rank is 3 with obtained of the routine method but has a scan time 326 seconds, the GRAPPA activation performed (mean rank 1) then the scan time can be reduced by 144 second and routine method with change the value of some parameters can reduce 150 second with a mean rank 2 .

Conclusion : There is no difference reveal HNP, spondilosis and degenerative disc ability between GRAPPA method and routine method with change the value of some parameters by routine methodProf. Dr. Margono Soekardjo hospital, but levels of clarity ligamentum flavum, thecal sac, intervertebra disc, corpus vertebra dan spinal cord is difference. Routine method Prof. Dr. Margono Soekardjo hospitalproduce images with the best quality, but has a maximum scan time.
\end{abstract}

Keywords : image quality, scan time, GRAPPA, MRI Parameters

\section{PENDAHULUAN}

Hasil penelitian oleh Perhimpunan Dokter Saraf Indonesia terhadap 14 rumah sakit pendidikan di Indonesia pada bulan Mei 2002 menunjukan 25\% dari kunjungan pasien merupakan kasus nyeri dan 35,85\% dari total kasus nyeri merupakan kasus nyeri punggung bawah (American College Of Radiology, 2011).

MRI vertebra lumbal menjadi salah satu modalitas imaging yang dipilih untuk mendiagnosa pasien dengan keluhan nyeri punggung bawah menggantikan myelografi dan CT vertebra lumbal (Blaimer, 2004). Salah satu hal yang dapat menurunkan kualitas gambar MRI dan pengulangan pemeriksaan adalah munculnya artefak. Motion artefact dapat diminimalkan dengan mengurangi scan time.

Pada MRI low tesla, upaya mengurangi scan time dapat dilakukan dengan teknik parallel MR Imaging. Pengisian $k$ space secara undersampling pada pMRI (contoh : GRAPPA), menyebabkan penurunan SNR dan munculnya artefact (Moeller, 2003). Tujuan penelitian ini adalah untuk mengetahui perbedaan kualitas gambar MRI 0,32 Tesla antara perlakuan parameter rutin dengan aktivasi GRAPPA dan perlakuan dengan perubahan nilai beberapa parameter rutin pemeriksaan MRI vertebra lumbal potongan sagital T2 FSE.

\section{METODE}

Jenis penelitian ini adalah quasi experiment dengan posttest only equivalent control group design. Teknik pengambilan sampel dengan consecutive sampling. Semua responden dilakukan scanning dengan 3 perlakuan yaitu perlakuan rutin yang dilakukan rumah sakit, perlakuan rutin dengan aktivasi GRAPPA dan perlakuan dengan perubahan beberapa parameter rutin. Parameter rutin yang dirubah antara lain Phase enc. Dir., FOV phase, TR, TE, NEX, concatenation, Base resolution, Phase resolution dan Bandwidth. Film hasil 
scanning diinterprestasi secara kualitatif dengan instrumen kuisoner oleh 2 (dua) dokter spesialis radiologi. Interpertasi pada kemampuan gambar MRI dalam menampakan kelainan HNP, spondilosis dan degenerative disc serta tingkat kejelasan ligamentum flavum, thecal sac, intervertebra disc, corpus vertebra dan spinal cord.

Penelitian ini dilakukan di instalasi Radiologi RSUD Prof. Dr. Margono Soekardjo Purwokerto pada bulan April Juni 2014. Jumlah sampel dalam penelitian ini adalah 25 responden. Dari 25 responden dihasilkan 75 gambar yang dinilai oleh observer yang dibagi menjadi 25 gambar hasil perlakuan rutin rumah sakit, 25 gambar hasil perlakuan parameter rutin dengan aktivasi GRAPPA dan 25 gambar hasil dari perlakuan rutin rumah sakitdengan perubahan nilai beberapa parameter rutin.

Pengolahan data dan analisis data menggunakan komputer yang dilengkapi windows. Analisis terdiri dari analisis univariat dan analisis bivariat. Analisa menggunakan uji Cochran untuk kemampuan menampakan kelainan dan uji Friedman untuk tingkat kejelasan obyek dengan program SPSS versi 16.

Penelitian ini telah memenuhi persyaratan etik dan telah disetujui untuk dilaksanakan penelitian dengan memperhatikan prinsip - prinsip yang dinyatakan dalam Pedoman Nasional Etik Penelitian Kesehatan (KNEPK) Departemen Kesehatan RI 2007 sesuai dengan surat keterangan Kelaikan Etik Komisi Etik Penelitian Kesehatan Fakultas Kesehatan Masyarakat Universitas Diponegoro.

\section{HASIL}

Perlakuan rutin rumah sakit membutuhkan waktu 326 sekon dengan voxel size $6,2775 \mathrm{~mm}$ untuk potongan sagital T2 WI FSE. Perlakuan dengan aktivasi GRAPPA dapat mereduksi scan time sebesar $44,17 \%$ dengan voxel size $6,2775 \mathrm{~mm}$ dan perlakuan rutin rumah sakit dengan perubahan beberapa nilai parameter rutin dapat mereduksi scan time sebesar 46,01\% dengan voxel size 7,1121 mm.

\section{Karakteristik Responden}

Distribusi responden berdasarkan usia menunjukkan bahwa responden paling banyak berusia $>40$ tahun sebesar $72 \%$, diikuti pada rentang usia 20-40 tahun dengan prosentase sebesar $20 \%$, sedangkan responden paling sedikit berasal dari kategori usia $<20$ tahun yaitu sebesar 8\%. Distribusi responden berdasarkan jenis kelamin sebesar $56 \%$ adalah wanita dan $44 \%$ adalah pria, hasil dapat dilihat pada tabel 1 .

Tabel 1 : Distribusi sampel berdasarkan usia dan jenis kelamin

\begin{tabular}{llcc}
\hline \multicolumn{2}{c}{ Karakteristik } & Frekuensi & Persentase (\%) \\
\hline \multirow{3}{*}{ Usia } & $<20$ & 2 & 8,00 \\
& $20-40$ & 5 & 20,00 \\
& $>40$ & 18 & 72,00 \\
\hline Jenis & Pria & 11 & 44,00 \\
Kelamin & Wanita & 14 & 56,00 \\
\hline
\end{tabular}

\section{Uji Kappa Interobserver}

Penilaian gambar MRI dilakukan oleh 2 orang dokter spesialis radiologi dengan pengalaman membaca gambar MRI lebih dari 6 tahun. Dari hasil uji kappa terhadap hasil penilaian kedua observer, diperoleh nilai koefisien kappa sebesar 0,957 dan $\mathrm{p}$ value 0,001 .Hasil tersebut menunjukan reliabilitas antar observer sangat baik.

\section{Analisa Data Univariat}

Analisis deskriptif kemampuan menampilkan gambaran HNP menunjukan dari 25 gambar MRI hasil perlakuan parameter rutin RSUD Prof. Dr. Margono Soekardjo Purwokerto didapatkan 24 gambar (96\%) menunjukan kelainan HNP, 1 gambar (4\%) menunjukan tidak adanya kelainan HNP. Dari 25 gambar MRI sampel hasil perlakuan parameter rutin RSUD Prof. Dr. Margono Soekardjo Purwokerto dengan aktivasi GRAPPA didapatkan 22 gambar (88\%) menunjukan kelaianan HNP, 3 gambar (12\%) menunjukan tidak adanya kelainan HNP. Dari 25 gambar MRI sampel hasil perlakuan perubahan beberapa nilai parameter rutin RSUD Prof. Dr. Margono Soekardjo Purwokerto didapatkan 23 gambar (92\%) menunjukan kelaianan HNP, 2 gambar $(8 \%)$ menunjukan tidak adanya kelainan HNP.

Analisis deskriptif kemampuan menampilkan gambaran spondilosis menunjukan dari 25 gambar MRI hasil perlakuan parameter rutin RSUD Prof. Dr. Margono Soekardjo Purwokerto didapatkan 20 gambar $(80 \%)$ menunjukan kelaianan spondilosis, 5 gambar (20\%) menunjukan tidak adanya kelainan spondilosis. Perlakuan parameter rutin RSUD Prof. Dr. Margono Soekardjo Purwokerto dengan aktivasi GRAPPA dan perlakuan dengan perubahan beberapa nilai parameter rutin memberikan nilai yang sama dengan perlakuan parameter rutin dalam kemampuan menampilkan kelainan spondilosis.

Analisis deskriptif kemampuan menampilkan gambaran spondilosis menunjukan dari 25 gambar MRI hasil perlakuan parameter rutin RSUD Prof. Dr. Margono Soekardjo Purwokerto dan perlakuan dengan perubahan beberapa nilai parameter rutin didapatkan 22 gambar (88\%) menunjukan kelainan degenerative disc, 3 gambar (12\%) menunjukan tidak adanya kelainan degenerative disc. Dari 25 gambar MRI sampel hasil perlakuan parameter rutin RSUD Prof. Dr. Margono Soekardjo Purwokerto dengan aktivasi GRAPPA didapatkan 20 gambar $(80 \%)$ menunjukan kelaianan degenerative disc, 5 gambar (20\%) menunjukan tidak adanya kelainan degenerative disc. Hasil perhitungan sebagai tabel 2.

\section{Analisa Data Bivariat}

Dari hasil uji Cochran dapat diketahui bahwa pada semua gambaran kelainan yang dinilai menghasilkan nilai $\mathrm{p}>$ 0,05, sehingga dapat disimpulkan bahwa tidak terdapat perbedaan yang bermakna secara statistik pada ketiga perlakuan terhadap kemampuan menampakkan gambaran HNP, spondilosis dan degenerative disc. Hasil uji Cochran antara perlakuan parameter rutin dengan aktivasi GRAPPA, perlakuan dengan perubahan nilai beberapa parameter rutin dan perlakuan parameter rutin terhadap kemampuan gambar 
dalam menampakan kelainan HNP, spondilosis dan degenerative disc ditampilkan dalam tabel 3.

Tabel 2 : Distribusi sampel berdasarkan kemampuan menampilkan gambaran kelainan HNP, spondilosis dan degenerative disc pada ketiga perlakuan

\begin{tabular}{|c|c|c|c|c|c|}
\hline \multirow[b]{2}{*}{ No } & \multirow[b]{2}{*}{ Kelainan } & & \multicolumn{3}{|c|}{ Scanning } \\
\hline & & & $\begin{array}{l}\text { Parameter } \\
\text { rutin } \\
\text { rumah } \\
\text { sakit }\end{array}$ & $\begin{array}{c}\text { Parameter } \\
\text { rutin rumah } \\
\text { sakit } \\
\text { dengan } \\
\text { aktivasi } \\
\text { GRAPPA }\end{array}$ & $\begin{array}{l}\text { Perubahan } \\
\text { nilai } \\
\text { beberapa } \\
\text { parameter } \\
\text { rutin }\end{array}$ \\
\hline \multirow{2}{*}{1} & \multirow{2}{*}{$H N P$} & Positif & $24(96 \%)$ & $22(88 \%)$ & $23(92 \%)$ \\
\hline & & Negatif & $1(12 \%)$ & $3(12 \%)$ & $2(8 \%)$ \\
\hline \multirow{2}{*}{2} & \multirow{2}{*}{ Spondilosis } & Positif & $20(80 \%)$ & $20(80 \%)$ & $20(80 \%)$ \\
\hline & & Negatif & $5(20 \%)$ & $5(20 \%)$ & $5(20 \%)$ \\
\hline \multirow{2}{*}{3} & \multirow{2}{*}{$\begin{array}{l}\text { Degenerative } \\
\text { disc }\end{array}$} & Positif & $22(88 \%)$ & $20(80 \%)$ & $22(88 \%)$ \\
\hline & & Negatif & $3(12 \%)$ & $5(20 \%)$ & $3(12 \%)$ \\
\hline
\end{tabular}

Tabel 3: Hasil uji Cochran kemampuan menampakan kelainan

\begin{tabular}{cll}
\hline No. & \multicolumn{1}{c}{ Kelainan } & p value \\
\hline 1 & $H N P$ & 0,368 \\
2 & Spondilosis & 1,000 \\
3 & Degenerative disc & 0,368 \\
\hline
\end{tabular}

Tabel 4 : Hasil uji friedman tingkat kejelasan obyek

\begin{tabular}{ccc}
\hline No. & Obyek & $\mathrm{p}$ value \\
\hline 1 & Ligamentum Flavum & $<0,001$ \\
2 & Thecal Sac & $<0,001$ \\
3 & Intervertebra Disc & $<0,001$ \\
4 & Corpus Vertebra & $<0,001$ \\
5 & Spinal Cord & $<0,001$ \\
\hline
\end{tabular}

Dari hasil uji Friedman dapat diketahui bahwa pada semua obyek yang dinilai menghasilkan nilai $p<0,001$ sehingga dapat disimpulkan paling tidak terdapat perbedaan yang bermakna secara statistik pada 2 perlakuan. Hasil uji Friedman ditampilkan dalam tabel 4 sedangkan analisa post hoc untuk uji Friedman adalah menggunakan uji Wilcoxon. bahwa :

Dari hasil uji Wilcoxon (tabel 5) dapat disimpulkan

a. Tingkat kejelasan obyek pada gambar hasil perlakuan parameter rutin berbeda dengan perlakuan parameter rutin dengan aktivasi GRAPPA.

b. Tingkat kejelasan obyek pada gambar hasil perlakuan parameter rutin berbeda dengan perlakuan perubahan beberapa nilai parameter rutin. c. Tingkat kejelasan obyek pada gambar hasil perlakuan perubahan beberapa nilai parameter rutin berbeda perlakuan parameter rutin dengan aktivasi GRAPPA.

Tabel 5 : Hasil analisa post hoc dengan uji Wilcoxon

\begin{tabular}{|c|c|c|c|}
\hline No. & Anatomi & Metode & $\mathrm{p}$ value \\
\hline 1 & $\begin{array}{l}\text { Ligamentum } \\
\text { Flavum }\end{array}$ & $\begin{array}{l}\text { Perlakuan dengan } \text { parameter } \\
\text { rutin - Perlakuan parameter } \\
\text { rutindengan aktivasi GRAPPA } \\
\text { Perlakuan dengan parameter } \\
\text { rutin - Perlakuan dengan } \\
\text { perubahan nilai beberapa } \\
\text { parameter rutin } \\
\text { Perlakuan parameter rutindengan } \\
\text { aktivasi GRAPPA - Perlakuan } \\
\text { dengan perubahan nilai beberapa } \\
\text { parameter rutin }\end{array}$ & $<0,001$ \\
\hline 2 & Thecal Sac & $\begin{array}{l}\text { Perlakuan dengan parameter } \\
\text { rutin - Perlakuan parameter } \\
\text { rutindengan aktivasi GRAPPA } \\
\text { Perlakuan dengan parameter } \\
\text { rutin - Perlakuan dengan } \\
\text { perubahan nilai beberapa } \\
\text { parameter rutin } \\
\text { Perlakuan parameter rutindengan } \\
\text { aktivasi GRAPPA - Perlakuan } \\
\text { dengan perubahan nilai beberapa } \\
\text { parameter rutin }\end{array}$ & $<0,001$ \\
\hline 3 & $\begin{array}{c}\text { Intervertebra } \\
\text { Disc }\end{array}$ & $\begin{array}{l}\text { Perlakuan dengan } \\
\text { rutin - Perlakuan parameter } \\
\text { rutindengan aktivasi GRAPPA } \\
\text { Perlakuan dengan parameter } \\
\text { rutin - Perlakuan dengan } \\
\text { perubahan nilai beberapa } \\
\text { parameter rutin } \\
\text { Perlakuan parameter rutindengan } \\
\text { aktivasi GRAPPA - Perlakuan } \\
\text { dengan perubahan nilai beberapa } \\
\text { parameter rutin }\end{array}$ & $<0,001$ \\
\hline 4 & $\begin{array}{c}\text { Corpus } \\
\text { Vertebra }\end{array}$ & $\begin{array}{l}\text { Perlakuan dengan parameter } \\
\text { rutin - Perlakuan parameter } \\
\text { rutindengan aktivasi GRAPPA } \\
\text { Perlakuan dengan parameter } \\
\text { rutin - Perlakuan dengan } \\
\text { perubahan nilai beberapa } \\
\text { parameter rutin } \\
\text { Perlakuan parameter rutindengan } \\
\text { aktivasi GRAPPA - Perlakuan } \\
\text { dengan perubahan nilai beberapa } \\
\text { parameter rutin }\end{array}$ & $<0,001$ \\
\hline 5 & Spinal Cord & $\begin{array}{l}\text { Perlakuan dengan parameter } \\
\text { rutin - Perlakuan parameter } \\
\text { rutindengan aktivasi GRAPPA } \\
\text { Perlakuan dengan parameter } \\
\text { rutin - Perlakuan dengan } \\
\text { perubahan nilai beberapa } \\
\text { parameter rutin } \\
\text { Perlakuan parameter rutindengan } \\
\text { aktivasi GRAPPA - Perlakuan } \\
\text { dengan perubahan nilai beberapa } \\
\text { parameter rutin }\end{array}$ & $<0,001$ \\
\hline
\end{tabular}


Untuk mengetahui perlakuan yang menghasilkan kualitas gambar paling baik dapat dilihat dari nilai mean rank pada tabel 6. Distribusi dari responden berdasarkan usia didapatkan hasil bahwa responden paling banyak berusia $>40$ tahun sebesar $72 \%$, diikuti pada rentang usia 20-40 tahun dengan prosentase sebesar $20 \%$, sedangkan responden paling sedikit berasal dari kategori usia $<20$ tahun yaitu sebesar $8 \%$. Distribusi responden berdasarkan jenis kelamin didapatkan responden sebesar $56 \%$ adalah wanita dan $44 \%$ adalah pria.

Tabel 6. Peringkat Kejelasan Obyek Pada Gambar MRI

\begin{tabular}{|c|c|c|c|c|c|}
\hline \multirow[b]{2}{*}{ Metode } & \multicolumn{5}{|c|}{ Obyek } \\
\hline & $\begin{array}{l}\text { Ligm. } \\
\text { Flavum }\end{array}$ & $\begin{array}{l}\text { Thecal } \\
\text { Sac }\end{array}$ & $\begin{array}{l}\text { Intervert. } \\
\text { Disc }\end{array}$ & $\begin{array}{l}\text { Corpus } \\
\text { Vertebra }\end{array}$ & $\begin{array}{l}\text { Spinal } \\
\text { Cord }\end{array}$ \\
\hline $\begin{array}{l}\text { Perlakuan } \\
\text { parameter } \\
\text { rutin. }\end{array}$ & 3 & 3 & 3 & 3 & 3 \\
\hline $\begin{array}{l}\text { Perlakuan } \\
\text { parameter } \\
\text { rutin } \\
\text { dengan } \\
\text { aktivasi } \\
\text { GRAPPA. }\end{array}$ & 1 & 1 & 1 & 1 & 1 \\
\hline $\begin{array}{l}\text { Perlakuan } \\
\text { perubahan } \\
\text { nilai } \\
\text { beberapa } \\
\text { parameter. }\end{array}$ & 2 & 2 & 2 & 2 & 2 \\
\hline
\end{tabular}

Proses degenerasi diskus dimulai pada umur 20 tahun (Cukke, 2010). Dari penelitian, umur termuda penderita degenerasi diskus adalah 16 tahun dan frekuensi terbanyak pada umur 40 - 50 tahun dan 61 tahun (Konsensusnasional III PERDOSSI, 2010). Perbandingan antara laki - laki dan perempuan yang terkena hernia diskus adalah $1: 1$ (McCullough, 2012).

Perlakuan dengan parameter rutin menghasilkan gambar dengan tingkat kejelasan paling tinggi untuk semua obyek yang dinilai, kemudian pada urutan kedua adalah perlakuan perubahan nilai beberapa parameter rutin, sedangkan perlakuan parameter rutin dengan aktivasi GRAPPA pada urutan ketiga.Namun untuk tingkat kejelasan spinal cord, perlakuan parameter rutin dengan aktivasi GRAPPA menghasilkan gambar yang lebih baik dibanding dengan gambar hasil perlakuan perubahan nilai beberapa parameter rutin.

Selain mempersingkat scan time, parallel MRI juga dapat menurunkan SNR dan menimbulkan ghosting artefact yang disebabkan perbedaan posisi pasien saat calibration acquisition dan parallel acquisition (Purwanto, 2003). Penurunan SNR terjadi pada pertengahan obyek karena bagian itu jauh dari permukaan coil (Ramachandran, 2014). Ukuran voxel perlakuan dengan perubahan nilai beberapa parameter rutin lebih besar, sehingga spatial resolution yang dihasilkan lebih rendah. Penurunan nilai bandwidth yang dilakukan, dapat meningkatkan chemical shif artefact pada spinal cord dan CSF.
Pengurangan nilai NEX pada perlakuan dengan perubahan nilai beberapa parameter rutin akan mereduksi scan time sebesar 46,01\% namun menurunkan SNR. Perlakuan parameter rutin dengan aktivasi GRAPPA dapat mereduksi scan time sebesar 44,17\% dengan cara acceleration factor 2 .

Dengan pengurangan scan time dengan prosentase tersebut, jika diterapkan akan sangat bermanfaat pada pasienpasien tertentu yang membutuhkan scan time yang singkat, seperti pasien yang tidak tenang namun keadaan umum pasien tidak memungkinkan dilakukan anestesi.

\section{SIMPULAN}

Responden sebagian besar berusia $>40$ tahun dan paling sedikit berusia $<20$ tahun. Proporsi responden lebih banyak pada wanita.

Tidak ada perbedaan yang bermakna secara statistik pada gambar yang dihasilkan dari metode parameter rutin rumah sakit, metode parameter rutin dengan aktivasi GRAPPA dan metode parameter rutin dengan beberapa perubahan nilai parameter (Phase enc. Dir., FOV phase, TR, TE, NEX, concatenation, Base resolution, Phase resolution dan Bandwidth) dalam menampakkan adanya gambaran kelainan HNP, spondilosis dan degenerative disc. Dari hasil uji cochran dihasilkan nilai $\mathrm{p}>0,05$. Ketiga metode akan menghasilkan gambar dengan interpertasi yang sama dalam menampilkan ada atau tidaknya gambaran HNP, spondilosis dan degenerative disc.

Ada perbedaan yang bermaknatingkat kejelasan obyek ligamentum flavum, thecal sac, intervertebra disc, corpus vertebra dan spinal cord pada gambar hasil perlakuanmetode parameter rutin rumah sakit, metode parameter rutin dengan aktivasi GRAPPA dan metode parameter rutin dengan beberapa perubahan nilai parameter. Hasil uji friedman dan analisa post hoc menghasilkan nilai $\mathrm{p}<0,001$. Gambar yang dihasilkan dari ketiga metode menunjukan gambaran ligamentum flavum, thecal sac, intervertebra disc, corpus vertebra dan spinal corddengan kejelasan gambaran obyek yang berbeda dari nilai mean rank dapat diketahui bahwa metode rutin rumah sakit menghasilkan kualitas gambar yang paling baik, kemudian diikuti gambar dari hasil perlakuan metode rutin dengan perubahan beberapa nilai parameter. Gambar hasil perlakuan metode rutin dengan aktivasi GRAPPA menghasilkan gambar dengan kualitas paling rendah.

\section{DAFTAR PUSTAKA}

American College Of Radiology. 2011. ACR Appropriateness Criteria Low Back Pain.

Blaimer M, Breuer F, Mueller M, Heidemann R.M, Griswold M.A and Jacob P.M. 2004. SMASH, SENSE, PILS, GRAPPA: How To Choose The Optimal Method. Rev Top MagnReson Imaging.Volume 15; No.4.

Cukke M.H, Ilyas M, Murtala B dan Liyadi F. 2010. Kesesuaian Antara Tanda-Tanda Degenerasi Diskus Pada Foto Polos Dengan Magnetic Resonace Imaging Lumbosakral Pada Penderita Nyeri Punggung Bawah.

Konsensus nasional III PERDOSSI. 2010. Diagnostik dan Penatalaksanaan Nyeri Kepala, Kelompok Studi Nyeri. 
McCullough BJ, Johnson GR, Martin BI and Jarvic JG. 2012. Lumbar MR Imaging And Reporting Epidemiology : Do Epidemiologic Data In Report Affect Clinical Management. Department Of Radiology And Neurologic Surgery. University Of Washington.

Moeller T. MRI Parameters And Positioning. Thieme. Stuttgart. New York. 2003

Purwanto E.T. 2003. Hernia Nucleus Pulposus Lumbalis Dalam : Meliala L. Suryamiharja A. Purba JS. Sadeli HA. Editors. Nyeri Punggung Bawah, Jakarta. Perhimpunan Dokter Spesialis Saraf Indonesia (PERDOSSI). p.133-48

Ramachandran T.S, Raghunathan U.I, Latorre J.G.S and Chang J.K, Disc herniation. http://www.emedicine.medscape.com. tanggal akses 28 April 2014 